\title{
IMPLANTAÇÃO DO PROGRAMA DE SAÚDE DA FAMÍLIA EM PORTO ALEGRE
}

Jussara Gue Martini'

\section{INTRODUÇÃO}

A organização dos serviços de saúde no Brasil, mesmo após a promulgação da Constituição de 1988, apresenta um perfil centralizado, com predomínio dos serviços privados, distante das reais necessidades de saúde da população brasileira e profundamente discriminatório e injusto. Este modelo de organização dos serviços de saúde, aliado a uma tentativa de dar mais atenção à O programa tem as características dos diferentes modelos políticos nos quais está sendo inserido, ao nível estadual e/ ou municipal.

prevenção do que à cura, fez com que o Ministério da Saúde apresentasse, em 1994, o Programa de Saúde da Família (PSF).

De acordo com a proposta do Ministério da Saúde, o PSF "é um modelo de assistência à saúde que vai desenvolver ações de promoção e proteção à saúde do indivíduo, da família e da comunidade, através de equipes de saúde, que farão o atendimento na unidade local de saúde e na comunidade, no nível de atenção primária" (BRASIL, 1994).

O objetivo proposto para o plano é a melhoria da saúde dos brasileiros e a implantação de um sistema que contemple a universalização da assistência, incluindo desde a proteção e a promoção da saúde até o diagnóstico e tratamento precoces das doenças. A meta de expansão do programa, colocada no projeto apresentado pelo ministério, é a de atingir todos os estados do país ao final do primeiro ano de implantação.

As necessidades de saúde da população de Porto Alegre, aliadas à crescente demanda por serviços em áreas carentes e a impossibilidade de investimentos maiores pela Prefeitura Municipal, levaram a Secretaria Municipal de Saúde a discutir a viabilidade de implantar no município o programa proposto pelo ministério.

Nosso objetivo, neste breve relato, é o de destacar aspectos básicos do processo de implantação do Programa de Saúde da Família no município de Porto Alegre, abordando, principalmente, os procedimentos na seleção das áreas atendidas e o processo de capacitação dos profissionais. Para tanto, realizamos uma rápida revisão da trajetória histórica do PSF, apresentamos os critérios de seleção das áreas do município que receberiam às equipes do programa e, finalizando, destacamos o perfil da equipe e sua capacitação.

\section{ASPECTOS HISTÓRICOS}

A estruturação do PSF começa a tomar forma em dezembro de 1993 quando, após uma reunião que tratava da "saúde da família", em Brasília, o então Ministro da Saúde, Dr. Henrique Santillo, cria um grupo de trabalho integrado por secretários estaduais e municipais de saúde, universidades, Serviço de Saúde Comunitária do Grupo Hospitalar Conceição, Coordenação do Programa Médico de

1 Professora do curso de Enfermagem da Universidade do Vale do Rio dos Sinos e especialização em Nutrição Clínica e Psicoterapia Psicanalítica - Unisinos. Doutora em Educação. Enfermeira da Secretaria Municipal de Saúde de Porto Alegre até 1999. 
Família, da Secretaria de saúde de Säo Paulo, UNICEF e OPAS, além de colaboradores do próprio ministério. O objetivo do grupo recém constituído era discutir a proposta de implantação de um modelo de saúde mais adequado às necessidades do pais.

As atividades do grupo deveriam responder às necessidades de mudança de um sistema de unidades básicas de saúde no qual Almeida (1991) identificou como modelo predominante o pronto atendimento, pautado na queixa-conduta, sem nenhum tipo de vínculo dos usuários com os serviços de saúde.

O Programa de Saúde da Família, lançado oficialmente pelo Ministério da Saúde em março de 1994, tem como objetivo, pelo menos no que se refere ao discurso, redirecionar esse modelo, fortalecendo atividades como a atenção domiciliar, trabalhos com grupos, palestras, orientações educativas e não somente consultas médicas e odontológicas de urgência ou programadas.

O programa proposto estimula a municipalização e a descentralização dos serviços, propiciando que o gerenciamento municipal dos recursos seja realizado de forma mais adequada e resolutiva. Cabe destacar, no entanto, que suas metas para o primeiro ano de funcionamento não foram alcançadas. Até 1995, 13 Estados tinham o PSF implantado em algum de seus municípios, quando o previsto era implantá-lo nos 26 Estados brasileiros e no Distrito Federal ainda em 1994, formando 2.500 equipes de trabalho, que atenderiam 2,5 milhões de famílias, consolidando um novo paradigma na atenção em saúde coletiva.

Apesar de não ter atingido a meta inicialmente estabelecida, o programa apresentava, em dezembro de 1999, 4.945 equipes instaladas em 1.870 municípios brasileiros, além de 21 pólos de capacitação credenciados, o que evidencia sua expansão por praticamente todo o território nacional.

\section{PROGRAMA DE SAÚDE DA FAMÍLIA EM PORTO ALEGRE}

O PSF em Porto Alegre, fundamenta-se em uma concepção de saúde entendida como síntese das condições de vida dos sujeitos. Visa, portanto, oferecer serviços de saúde à população submetida a situações de alto risco sócio-sanitário, priorizando áreas geográficas selecionadas com base em indicadores de concentração de pobreza. Assim, o PSF, em Porto Alegre, preenche os vazios de serviços de áreas de grandes carências sociais e sanitárias (De Negri Filho et al., 1995).

Pautados por esses princípios, um grupo de profissionais da Secretaria Municipal de Saúde de Porto Alegre e do Serviço de Saúde Comunitária do Grupo Hospitalar Conceição, iniciam, em junho de 1995, a elaboração conjunta de um projeto de instalação do programa no município.

O grupo de trabalho organiza em Porto Alegre, em julho de 1995, o Seminário Internacional: $A$ saúde da família e a qualificação do modelo assistencial do SUS, tendo o apoio do Ministério da Saúde, do Conselho de Saúde Britânico, do Conselho Municipal de Saúde de Porto Alegre, da Federação das Associações dos Municípios do RGS (FAMURGS), do Fundo das Nações Unidas para a Infância (UNICEF), do Ministério da Saúde de Cuba, das Universidades de Londres e de Toronto, entre outras instituições públicas e privadas, nacionais e internacionais.

A marcante participação da população no evento, principalmente dos conselheiros locais e municipais de saúde, explicitou o desejo da população de participar do projeto de atenção à saúde proposto pelo Programa de Saúde da Família.

O projeto elaborado estabelece os objetivos do programa, os critérios de implantação das unidades, a composição e perfil das equipes, o processo de seleção e capacitação dos profissionais, os convênios e a estrutura física das unidades. Os objetivos, atendendo aos aspectos já mencionados, incluem a instalação de serviços de saúde em áreas desprovidas de assistência, promover a integração dos serviços em um sistema municipal de saúde redefinido e resolutivo, criando um centro de referência regional para a formação de recursos humanos nesta área.

As discussões iniciais do grupo centraram-se na definição dos critérios de seleção dos locais para implantação das unidades. A fragilidade e pouca abrangência dos dados disponíveis sobre a situação sócio-sanitária das comunidades do município dificultava a tomada de decisões. O grupo utilizou, então, dados do Instituto Brasileiro de Geografia e Estatística (IBGE), desdobrados por setor censitário e agregando dados do Departamento Municipal de Habitação (DEMHAB) sobre áreas de 
Implantação do Programa de Saúde da Família em Porto Alegre.

assentamentos. Esses indicadores foram complementados com dados epidemiológicos das Declarações de Óbitos, do Sistema Nacional de Nascidos Vivos (SINASC) e dos Programas de Crianças e Gestantes em Risco Nutricional, construindo, assim, um mapeamento das diferentes regiões do município e suas carências de serviços de saúde.

Desse modo, mapeadas as áreas, foram mobilizados os conselhos locais de saúde, associações de moradores e demais entidades comunitárias a fim de visitar as áreas indicadas, compatibilizando os critérios iniciais com as peculiaridades das comunidades e com a aceitação do programa pela comunidade. Definidos os locais de implantação, tinha início o processo de negociação dos convênios entre a Prefeitura Municipal de Porto Alegre (PMPA) e as associações comunitárias legalmente. constituídas para repasse de recursos para o pagamento dos profissionais das equipes do PSF. Os convênios estabelecidos são monitorados e geridos por um Comitê Gestor, integrado pelas associações comunitárias conveniadas e a PMPA.

Os levantamentos iniciais apontaram que, para atender os 460.000 cidadãos excluídos do município, seria necessário instalar 200 equipes de saúde da família. O projeto inicial previa instalar a metade, 100 equipes em 1995/1996, com uma possível complementação em 1997/1998. No entanto, foram instaladas 28 equipes até 1999, com uma previsão de instalar mais 10 equipes no ano 2000.

Concluído o projeto, sua apresentação e discussão pelos Conselhos Locais Interinstitucionais de Saúde (CLIS) ocorreu de agosto a setembro de 1995, acompanhadas das visitas conjuntas aos locais previstos para instalação das equipes. A aprovação do Programa de Saúde da Família de Porto Alegre pelo Conselho Municipal de Saúde (CMS), ocorreu em 21 de setembro de 1995, seguida da instalação da Comissão de seleção dos profissionais para composição das equipes.

O processo de seleção obedeceu às prescrições legais da PMPA, realizando divulgação por edital do concurso público, inscrições de candidatos, homologação das inscrições, prova escrita, entrevista dos aprovados na prova, capacitação e prova prática, realizadas no período de janeiro a março de 1996 para médicos, enfermeiros e auxiliares de enfermagem e de junho a julho de 1996 para seleção dos agentes comunitários.

A fase seguinte, na constituição das equipes, foi o processo de capacitação, realizado em conjunto pela Secretaria Municipal de Saúde e o Serviço de Saúde Comunitária do Grupo Hospitalar Conceição, mantendo a parceria iniciada na elaboração do projeto de implantação.

É importante destacar que, paralelamente ao processo de implantação do PSF, Porto Alegre vivia a consolidação da municipalização plena, promovendo a reorganização de seus serviços de saúde através da distritalização, criando as gerências distritais, buscando construir um sistema minimamente hierarquizado e resolutivo; fortalecendo os mecanismos de participação e controle social como os Conselhos Locais e o Conselho Municipal de Saúde, a fim de possibilitar a gestão local compartilhada, articulando as propostas dos conselhos de saúde com as decisões do Orçamento Participativo e com as Conferências municipais de saúde. Deste modo, enfatiza princípios organizativos sanitários vinculados à singularidade de cada local em um movimento de combate ao "universalismo excludente" que caracteriza o modelo vigente (Assis,1996).

O programa de Saúde da Família, na proposta construída em Porto Alegre, visa contrapor-se a este modelo, mudando o foco da equipe, da doença para a saúde. No entanto, parte significativa dos profissionais possui uma formação centrada no modelo biomédico, sendo, por isso, primacial o processo de capacitação das equipes.

No caso de Porto Alegre, as equipes foram constituídas por um médico, um enfermeiro, dois auxiliares de enfermagem e quatro agentes comunitários; cada equipe é responsável pelo atendimento de 800 a 1000 famílias, residentes em uma área geográfica delimitada como área de atuação.

O objetivo do processo de capacitação inicial, como primeira etapa de um processo de educação continuada, é "qualificar os profissionais selecionados para sua atuação no programa de saúde da família, sensibilizando-os para a prática da reflexão sobre a própria experiência, gerando novas práticas de atenção em saúde" (Sudbrack, 1996, p. 7).

As ações de capacitação desenvolvidas consideraram as necessidades da equipe:

\# conhecer a realidade das famílias de sua área de atuação, identificando parâmetros sociais, demográficos, culturais e epidemiológicos; 
\# realizar o diagnóstico de saúde da comunidade, identificando problemas prevalentes e estabelecendo prioridades;

\# desenvolver um planejamento participativo das ações prioritárias de saúde;

\# implantar processos permanentes de educação em saúde;

\# definir mecanismos de controle social e avaliação das atividades da equipe;

\# registrar as atividades desenvolvidas nos formulários próprios, de modo a gerar dados que alimentem as informações epidemiológicas locais, regionais e nacionais.

O processo de capacitação inicial, considerando as necessidades apontadas, tem como preocupações fundamentais: a integração das equipes; a análise crítica e a compreensão da realidade sócio-sanitária da cidade e de suas áreas de atuação; a apresentação e discussão das políticas públicas de saúde, em âmbito municipal, estadual e federal, bem como, a análise das interdependências e conexões entre os diferentes níveis e o exame dos dados clínico epidemiológicos indispensáveis ao desenvolvimento das ações de saúde de cada equipe (Sudbrack, 1996).

A metodologia de trabalho esteve organizada em quatro módulos teórico-práticos, com duração de três semanas, nos turnos da manhã e tarde. As atividades incluíram o diagnóstico de saúde da área de atuação de cada equipe e o cadastramento das famílias, possibilitando a organização inicial dos processos de trabalho (Anexo I).

A abordagem do processo ensino-aprendizagem esteve fundamentada na metodologia participativa/ problematizadora, inserida na pedagogia freireana, considerando os sujeitos da aprendizagem como capazes de analisar, criticar e superar os problemas de seu cotidiano profissional, manejando os conflitos em direção a uma posição de consenso, respeitando as diversidades da população assistida.

O processo de capacitação inicial foi desenvolvido por profissionais das diversas áreas envolvidas nas duas instituições promotoras e por profissionais convidados.

O eixo central do PSF é a atuação integrada das equipes, em parceria com sua comunidade e os diversos segmentos da sociedade. Assim, é fundamental que estes aspectos integrem um programa de educação continuada que articule questões formativas e informativas. No caso do PSF de Porto Alegre, a capacitação tem sido uma constante, abrangendo aspectos como a discussão da participação popular, coleta e registro de dados e programas específicos, como, por exemplo, o de imunizações, o Pra-nenê, risco nutricional, entre outros.

\section{CONCLUSÕES}

A busca de um atendimento à saúde de melhor efetividade tem estimulado e gerado transformações no setor saúde do país, marcadamente desde a década de 80 . No marco das Conferências Nacionais de Saúde, das Ações Integradas de Saúde (AIS), do Sistema Unificado e Descentralizado de Saúde (SUDS) e do Sistema Único de Saúde (SUS), movimentos esses apoiados pelas diretrizes da municipalização e descentralização, ampliaram-se os debates sobre cuidados primários em saúde, distritalização, territorialização, hierarquização dos serviços, do acesso, da equidade, ainda tão distantes em alguns casos.

A complexidade do sistema de saúde tem dificultado as possibilidades de unificação, caracterizada "pela pluralidade de sistemas adaptados às respectivas realidades locais, possuindo; todos eles, elos de ligação que permitam a articulação em um verdadeiro sistema de saúde" e não focos de doença como temos hoje (Campos, 1996, p. 4). É no marco desta concepção que hoje incluímos o PSF como um elo deste sistema. Caso contrário, corremos o risco de criar um sistema de saúde para pobres, com baixo aporte de recursos tecnológicos, pouca resolutividade e desarticulado dos princípios do sistema único de saúde.

Certamente, a construção social do SUS não vem palmilhando um caminho linear. Ela tem se constituído, pelo contrário, "em uma árdua jornada (...) num sucessivo construir e desconstruir no enfrentamento de variados desafios, mas vem apresentando algumas experiências relevantes e inovadoras (...)" (Cohn; Elias, 1998, p. 113). Nesse sentido, as diretrizes ético-políticas do SUS tomam distintas feições ao se transformarem em projetos operativos dos sistemas locais de saúde, com o PSF não é diferente, o programa tem as características dos diferentes modelos políticos nos quais 
está sendo inserido, ao nível estadual e/ou municipal.

A continuidade e a generalização do programa, tal como está previsto no projeto inicial do ministério, vincula-se, em grande medida ao controle social das políticas de saúde pública, envolvendo, sobretudo, a participação popular, como caminho para a democratização da sociedade e construção da cidadania. Dadas estas condições, podem estas experiências com a implantação e qualificação do PSF, ao se desenvolverem, traduzir-se em importantes canais de mobilização para uma sociedade e um Estado mais democráticos e efecientes no cumprimento das políticas públicas de saúde.

\section{REFERÊNCIAS BIBLIOGRÁFICAS}

ALMEIDA, M. C. P. de. O trabalho de enfermagem e sua articulação com o processo de trabalho em saúde coletiva - Rede básica de saúde em Ribeirão Preto. Ribeirão Preto: Universidade de São Paulo, 1991. Tese (Livre Docência) - Escola de Enfermagem de Ribeirão Preto.

ASSIS, Marluce Maria. O fazer da enfermeira no sistema local de saúde: individual ou coletivo? Revista Brasileira de Enfermagem. Brasília, v. 49, n. 3, p. 363 - 372, jul./set. 1996.

BRASIL, Ministério da Saúde. Fundação Nacional de Saúde. Departamento de operações. Coordenação de saúde da comunidade. Programade Saúde da Família. Brasília: Ministério da Saúde, 1994.

CAMPOS, Gastão Wagner de Souza. Análise crítica das contribuições da saúde coletiva à organização das práticas de saúde do SUS. São Paulo: Unicamp, 1996 (mimeogr.).

COHN, Amélia; ELIAS, Paulo E. Saúde no Brasil: políticas e organização dos serviços. 2. ed. São Paulo: Cortez: Cedec, 1998.

DE NEGRI FILHO, Armando et al. Programa de saúde da familia em Porto Alegre -RS. Porto Alegre: Secretaria Municipal de Saúde: SSC-GHC, 1995. (mimeogr.).

SUDBRACK, Mirtha Sendic (Org.). Capacitação das equipes do PSF de Porto Alegre. Porto Alegre: Secretaria Municipal de Saúde:SSC-GHC,1996. (mimeogr.). 


\section{ANEXO I \\ Capacitação inicial - equipes Programa de Saúde da Família \\ Programação: 23.08 a 13.09 .96 , das $08 \mathrm{~h}$ as $17 \mathrm{~h}$.}

23.08.96 - 14h - Abertura oficial da capacitação com presença das autoridades ligadas ao programa.

26.08.96 - História do PSF no mundo e no Brasil.

- As bases do SUS em Porto Alegre. Bases para um sistema municipal de saúde. Relato de experiência do Grupo Hospitalar Conceição -GHC.

27,28 e 29.08.96 - As estratégias e conceitos chave para o enfoque geral e comunitário. Uma proposta metodológica que aborda as questões de educação, psicologia de grupo e técnicas de abordagem comunitária.

30.08.96 - Oficina de territorialização e resgate da historicidade do espaço/população.

- Primeira visita ao terreno.

02,03.09.96 - Manhã - Ações programáticas essenciais.

- Normas e rotinas - padrão mínimo das unidades básicas de saúde.

- Supervisão integrada e consultores distritais.

03.09.96 - tarde - Oficina de territorialização - coleta de dados. (continuação).

04.09.96 - Manhã - Sistema de informações: registros, prontuários e agendamentos.

Tarde - Sistema administrativo da Secretaria Municipal de Saúde.

- Abastecimento e manutenção.

05,06.09.96 - Manhã - Vigilância em saúde.

02,05,06.09.96 - Tarde - Trabalho de campo: apresentação das equipes às lideranças comunitárias, reconhecimento do posto, territorialização, cadastramento das famílias e organização do serviço.

09 a 13.09.96 - Capacitação em temas técnicos:

Manhãs: para os médicos: prática médica comunitária em geral.

$\mathrm{P} /$ enfermeiros: triagem, consulta de enfermagem, prescrição de medicamentos e curso de supervisão de agentes comunitários.

$\mathrm{P} /$ auxiliares de enfermagem: atualização nos procedimentos de enfermagem, em especial os de saúde coletiva.

P/ agentes comunitários: capacitação coordenada pelo Ministério da saúde.

Tardes: Trabalho de campo: territorialização e cadastramento das famílias e organização do serviço. 